Artigo original

Hegemonia - Revista Eletrônica de Relações Internacionais do Centro Universitário Unieuro

ISSN: $1809-1261$

UNIEURO, Brasília, número 10, 2012, pp. 127-157.

Recebido em: 13/4/2012

Revisado em: 8/5/2012

Aprovado em: 19/6/2012

\title{
Segurança pública, segurança interna e segurança cidadã: pontos convergentes e discordantes
}

Seguridad pública, seguridad interna y seguridad ciudadana: puntos convergentes y discordantes

REZENDE, Alessandro ${ }^{1}$

Resumo: O artigo tem o propósito diferenciar os conceitos impostos à segurança pública, segurança interna e polícia comunitária. A intenção é dimensionar melhor o primeiro conceito (segurança pública) para, então, estabelecer parâmetros para atualizá-los. Este posicionamento é necessário para que se possa entender as relações dos Estados depois da Segunda Guerra Mundial e também o pós Guerra Fria. Após esses fatos, os Estados Unidos passaram a ser hegemônicos e, consequentemente, a propagar essa hegemonia pelo mundo. Antes de definir os conceitos é essencial entender as autonomias que alcança os países. Que tipo de força é preciso para enfrentar as ameaças: exército, polícia ou guarda nacional e que tipo de papel desenvolvem no cenário nacional. Por exemplo, Costa Rica não tem exército, mas tem um plano de defesa em que utiliza outras instituições para enfrentar suas ameaças.

1 Doutorando em Ciências Sociais, mestre em ciência política. Contato: alessandroligadf@gmail.com 
Artigo original

Hegemonia - Revista Eletrônica de Relações Internacionais do Centro Universitário Unieuro

ISSN: $1809-1261$

UNIEURO, Brasília, número 10, 2012, pp. 127-157.

Palavras chaves: segurança pública, segurança interna, polícia comunitária e mudanças institucionais.

$\begin{array}{llcl}\text { Abstract: } & \text { This article is } \begin{array}{c}\text { intended to } \\ \text { the concepts imposed on public safety, homeland }\end{array} \text { security and }\end{array}$ community policing. The intention is to size the better the first concept (public safety) to then establish parameters to update them. This position is required to be able to understand the relations of States after the Second World War and also the post-Cold War. After these facts, the United States became hegemonic and thus spreading its hegemony over the world. Before defining the concepts is essential to understand the autonomy that reaches countries. What kind of force is needed to meet the threats: the army, police or national guard and what kind of role in developing the national scene. For example, Costa Rica has no army, but have a defense plan that uses other institutions to cope with their threats.

Keywords: public safety, homeland security, community policing and institutional changes.

\section{Introducción al tema de la Seguridad pública}

El tema que conceptualiza la seguridad pública siempre fue confuso en América Latina debido a inestabilidad política que sufrió y sufre los países latinos. Por ejemplo, en las décadas de 60 y 70, periodo en que las dictaduras militares, fue un periodo de gran confusión sobre que doctrinas serian utilizadas para combatir el avance del comunismo. Para Neto (2008) las doctrinas de seguridad interna y 
Artigo original

Hegemonia - Revista Eletrônica de Relações Internacionais do Centro Universitário Unieuro

ISSN: $1809-1261$

UNIEURO, Brasília, número 10, 2012, pp. 127-157.

nacional fueron metodológicamente salvadas por los gobiernos desempeñadas por cuerpos policiales y las fuerzas armadas.

El esencial de la seguridad pública es organizado y su operativo es hecho por instituciones del Estado. La seguridad pública no se puede ser hecha por empresas privadas, estas pueden participar pero la seguridad pública es una acción típicamente del Estado-Nación. Para la seguridad pública no correcta afirmar que solamente son realizada por fuerzas policiales que desarrollan una metodología contra un enemigo. Las fuerzas armadas también participan del proceso. Incluso, según Dammert (2007), en muchas realidades latinas, las fuerzas armadas son utilizadas para reforzar la seguridad pública, cuando son convocadas. Sin embargo, esta situación puede ocurrir en regímenes democráticos o no. Una de las principales características de este tema es equiparar la práctica de los organismos del Estado que a las acciones que les imputan en búsqueda para identificar las amenazas.

Conforme Urgate (2004) la constitución de amenazas lleva a otro concepto: "la condición objetiva de amenazas de las aludidas circunstancias, sino de un hecho social: la asunción por parte de la comunidad de que se trataba, de que tales circunstancias constituyen amenazas, acto que denominan seguritización" (2004: 80). La amenaza existencial lleva a medidas extras que tienden a caracterizar la seguritización que lleva a una solución adecuada.

El autor señala que el tema de seguridad tiene un enfoque constructivista donde, en una visión realista, cuestiona la justificación 
Artigo original

Hegemonia - Revista Eletrônica de Relações Internacionais do Centro Universitário Unieuro

ISSN: $1809-1261$

UNIEURO, Brasília, número 10, 2012, pp. 127-157.

del acto delante de las amenazas. Algunos autores disponen que el tema de seguridad está relacionado directamente a los cuerpos policiales (Pontón, 2009; Neto, 2008; Cano, 2006 en: Fundación Friedrich Ebert) y no a las fuerzas armadas. De esta forma, lo extremado concepto para entender lo que sea seguridad pública sea complicado.

Para Urgate, los estudios tradicionales sobre seguridad hacen que el actor militar desaparece con el dinamismo dos conceptos sobre el asunto. Los cambios y también la amplitud sobre las amenazas formalizan esta nueva posición constructivista (2004: 85). Según el autor, la participación de los militares pasaron a ter también carácter político por estos militares asumieren puestos muchos más políticos que propiamente por cuenta de la nueva agenda de las fuerzas armadas con los objetivos de identificación do que sea amenaza: "(...) La agenda militar tiene entonces su propia distinta lógica e imperativos lógicos, pero no opera aisladamente. La interrelación entera de capacidades militares entre los Estados está profundamente condicionada por las relaciones políticas..." (2004: 86).

De esta forma la agenda de las fuerzas armadas direccionaron para prácticas das relaciones internacionales para conocer los contextos mundiales, necesarios para la nueva demanda del Estado. Así se descubre que la caracterización del "enemigo" y las amenazas toman dimensiones bien más grandes. De esta forma puede comprender las medidas que ocurrirán después del 11 de septiembre 
Artigo original

Hegemonia - Revista Eletrônica de Relações Internacionais do Centro Universitário Unieuro

ISSN: $1809-1261$

UNIEURO, Brasília, número 10, 2012, pp. 127-157.

donde fue creado un nuevo modelo nacional estadounidense para encontró el enemigo del Estado. Medidas distintas fueron tomadas para evitar que amenazas antes no llevadas en cuenta pudiese ser tomada.

Políticas más duras fueron puestas en acción para controlar el caos evidenciado. De esta forma, otras instituciones pasaron a enfrentar también los confronto sobre la amenaza establecida. Para Vélez (2008) las nuevas amenazas fueron establecidas después de "las tensiones producidas entre corrientes teóricas estatocéntricas y antropocéntricas sobre el tema de seguridad" (2008: 13). El autor pone en discusión diversas problemáticas que fueron originadas desde el fin de la Guerra Fría y también de la globalización y que las políticas exteriores transformaron las políticas públicas de los Estados, observando la teoría realista.

Ya para el Centro de Estudios Legales y Sociales (2004): "es propio de toda política pública abarcar la pluralidad, ya sea en el campo económico, laboral, educativo, etc." (2004: 15). Esto facto dimensiona el tamaño del contexto de la seguridad pública y también de los actores involucran en este escenario. Pero este trabajo busca identificar donde se posicionan las instituciones y sus actores para donde direccionan sus acciones.

Para Dammert (2007) la actuación de las fuerzas armadas no tiene un límite definitivo. La autora pone ejemplo las "dictaduras en el Cono Sur, las guerras civiles en Centroamérica o incluso en procesos de crisis institucionales (como en Ecuador y Perú), los 
Artigo original

Hegemonia - Revista Eletrônica de Relações Internacionais do Centro Universitário Unieuro

ISSN: $1809-1261$

UNIEURO, Brasília, número 10, 2012, pp. 127-157.

militares tienen una larga historia de intervencionismo en temas de seguridad pública" (2007: 119). Con este posicionamiento se queda más claro que también es necesario entender os escenarios de estabilidad política de cada país para entonces delimitar las leyes sobre seguridad del Estado.

Las reglas de juego y el restablecimiento de la democracia se pone diversas perspectivas a serem aclaradas: multiculturalismo, institucionalismo, cultura de conflictos políticos, etc. Para Vélez (2008) estos tópicos son necesarios ser analizados porque así se estudia las perspectivas y dinámicas de cada Estado. Por ejemplo, lo que pasó en el día 30 de septiembre de 2010 en Ecuador.

La institución de la Policía Nacional inició un movimiento de reivindicación contra la Ley de los Servidos que debería ser sancionada en esto día. Por cuenta de esta manifestación se creó una crisis del Estado ecuatoriano donde el presidente por mucho poco no fue asesinado por los policías, generando un escenario de complejidad institucional que no fue direccionado solamente para el gobierno, pero, principalmente para el Estado causando daño a la democracia estatal. Según Orozco (2006) esta situación puede ser entendida como que "la amenaza militar implica un recurso a la capacidad material y efectiva de las fuerzas de una nación para garantizar la integridad del territorio frente a fuerzas que pretendan desquebrajar la unidad del Estado" (2006: 169). Pero la amenaza fue la fuerza que debía mantener la orden pública: la policía. 
Artigo original

Hegemonia - Revista Eletrônica de Relações Internacionais do Centro Universitário Unieuro

ISSN: $1809-1261$

UNIEURO, Brasília, número 10, 2012, pp. 127-157.

Para Vélez hay que observar los "escenarios de complejidad, derivados de la conjunción de muchos factores externos e internos, están generando la reorientación de las misiones militares hacia otras actividades no relacionadas con la defensa" (2008: 19). En estas reorientaciones de las misiones militares fue ocurrida en el día de 30 de septiembre cuando las fuerzas armadas para mantener la orden pública enfrentó las fuerzas policiales que dejaron el presidente en "estado de secuestro" dentro del hospital de la policía. Fue una verdadera batalla donde las fuerzas se enfrentaron, literalmente, a una balacera. De un lado estaba el Ejército del Ecuador salvando el presidente, y de lo otro lado estaba la policía contraria a liberación del mandatario.

Pero una de las cosas que deben ser resaltadas al tema de seguridad pública está referida al plan de defensa, donde los países latinos $^{2}$ mantienen en su política exterior un plan de defensa manteniendo la agenda de seguridad como una de las actividades del Estado. Un plan de defensa también está direccionado al plan de desarrollo de cualquier país y esto vuelve para la cuestión vital de estrategia, donde esta aborda una metodología para mantener la eficacia en percepción de problemas internos y externos, identificando las amenazas-enemigos. La amenaza está en función de la percepción y por esto se identifica la teoría constructivista y no realista y así se consiga diferéncialas.

2 Solamente Costa Rica no tiene Ejército entre los países latinos, mismo así, hay estratégica de seguridad. 
Artigo original

Hegemonia - Revista Eletrônica de Relações Internacionais do Centro Universitário Unieuro

ISSN: $1809-1261$

UNIEURO, Brasília, número 10, 2012, pp. 127-157.

El concepto de seguridad nacional utiliza la teoría del Realismo porque es una cadena estatocéntrica: el Estado institución arriba de intereses personales. Hobbes al escribir Leviatán, pone la situación de la seguridad con una relación a la Filosofía en el momento el Estado mantiene la integridad del ciudadano y la anarquía del mundo. Fue esta escuela hobbesiana que influencia el Realismo.

Para Kant, Hobbes no estaba totalmente correcto porque se el Estado es central en el tema de seguridad, el caos con el ordenamiento jurídico internacional sobresale porque hasta donde puede ir la actuación del Estado con el argumento jurídico. Según Orozco (2006), "Kant ve que la única vía para lograr seguridad es crear un ordenamiento jurídico internacional semejante al que hay en el interior de los estados" (2006: 165). En contexto del Realismo y Neorrealismo el objeto de la seguridad tendrá relación con la integridad territorial del Estado y también el interés de la nación. Para la teoría constructivista, hay una crítica a la postura porque el interés nacional es identidad de una sociedad en su interacción genera construcción social. El sistema internacional es producto de lo que hacen sus actores en una dinámica crean identidades que definan sus interés y su posición en el sistema. El constructivismo está en medio de la propuesta de que para identificar la amenaza es necesario comprender la vulnerabilidad y el riesgo involucrado.

Para Urgate (2004) el concepto de amenaza se cambia con el tiempo y por esto la modernización del tema de seguridad pública tiene también que modernizar para acompañar los nuevos escenarios. 
Artigo original

Hegemonia - Revista Eletrônica de Relações Internacionais do Centro Universitário Unieuro

ISSN: $1809-1261$

UNIEURO, Brasília, número 10, 2012, pp. 127-157.

El autor va más allá de la realidad para entender "la expresión seguridad pública o seguridad interior haciendo referencia a la seguridad concebida dentro del ámbito del Estado, relacionada con la protección del ejercicio de los derechos individuales de la persona, de su vida y de sus bienes" (2004: 6). Para el autor, lo concepto de seguridad pública abarca lo concepto de defensa nacional.

Para el institucionalismo neoliberal de Kechane (...) esta teoría está presente en la posición interdependiente que mira la cooperación en anarquía y reciprocidad en seguridad compartida. Las acciones estatales dependen de acuerdos institucionales prevalecientes. Para Orozco (2006), "la seguridad es asumida como una cualidad de los sujetos que están libres de amenazas o de agresiones a su individualidad" (2006: 163). El autor dispone la administración pública como herramienta para mantener la seguridad de los ciudadanos, en sentido de un adjetivo de seguro. En esto sentido el concepto de seguridad es un "instrumento del poder político" (2006: 164) a nivel de un sistema internacional motivados por la globalización. La seguridad pública aparece como un bien público a partir de una concepción de que las amenazas contra el ser humano tienen contextualización central de los actos estatal.

Con estas ideas, aparecen teorías que utilizan conceptos minimalistas (reducir violencia por actores estatales y no estatales) y maximalistas (liberación del temor y necesidades del Programa de las Naciones Unidas para el Desarrollo, PNUD, por más desarrollo de los países) para entender la seguridad, de acuerdo a Legler (2003). La 
Artigo original

Hegemonia - Revista Eletrônica de Relações Internacionais do Centro Universitário Unieuro

ISSN: $1809-1261$

UNIEURO, Brasília, número 10, 2012, pp. 127-157.

convivencia pasa a ser entendida como fenómeno sociológico. Por esto que el entendimiento pasa a concentrado en que el Estado es quien da garantías a los ciudadanos, pero al mismo tiempo viola ese principio al no mantener esas garantías, en los paises latinos. Es claro que en otros paises ese tema tiene otro contexto, como por ejemplo Canadá.

Según Fuentes (2005), fue la creación de la Comisión de Seguridad Humana, en enero de 2001, propuesta por el Secretario de la ONU, Koff Annan, que nuevas directrices fueron ofrecidas. Lo que es interesante aquí, que esta medida aconteció algunos meses antes del ataque de las torres gemelas. La autora destaca tres medidas que cambiaron las nociones del tema: a) "promover el entendimiento público de la seguridad humana y de los imperativos que esta perspectiva conlleva, b) desarrollar el concepto de seguridad humana como una herramienta operativa para la formulación y aplicación de políticas, c) proponer un programa de acción con miras a determinara las medidas más convenientes para enfrentar las amenazas a la seguridad humana" (2005: 28). Esta nueva visión sobre seguridad tenía el propósito de desarrollar medidas una vez que los problemas de la seguridad pasaron a ser mucho más complejos y así colocar el entendimiento de que el Estado debe incluir la seguridad de las personas como eje central para otras demandas.

Aquí se menciona que para identificar las amenazas quiere decir que hay peligros contra las personas y que medidas deben ser creadas para sanar tales males. Fuentes desarrolló varios ítems para 
Artigo original

Hegemonia - Revista Eletrônica de Relações Internacionais do Centro Universitário Unieuro

ISSN: $1809-1261$

UNIEURO, Brasília, número 10, 2012, pp. 127-157.

identificar los peligros para toma de decisiones: "protección de las personas en conflictos violentos, protección y potenciación de las personas que migran o son desplazadas, protección y potenciación de las personas en situaciones posteriores a los conflictos, inseguridad económica, la posibilidad de elegir entre distintas oportunidades, la salud como elemento de la seguridad humana, conocimientos, preparación para la vida y valores como elementos de la seguridad humana" (2005: 30).

Esta amplitud sobre la actuación de la seguridad pública el derecho de la vida para las personas como un asunto de lo "debería ser", concepción idealista, con la responsabilidad de proteger y también de la soberanía del Estado, pero que presiones exteriores motivaron el cumplimento de estas medidas. Por ejemplo es deber de lo país miembro ir contra los asesinatos masivos, las violaciones de los principios de los derechos humanos. Todos estos temas orientados a la soberanía del Estado, sabiendo que "la soberanía de un Estado conlleva responsabilidades e incumbe al propio Estado la responsabilidad principal de proteger a su población" (2005: 32).

\section{Seguridad Interna}

Es siempre bueno frisar que el fin de la Guerra Fría, la caída del Muro del Berlín (noviembre de 1989) a fuera otros acontecimientos, 
Artigo original

Hegemonia - Revista Eletrônica de Relações Internacionais do Centro Universitário Unieuro

ISSN: $1809-1261$

UNIEURO, Brasília, número 10, 2012, pp. 127-157.

crearon escenarios políticos distintos para el mundo, principalmente en el tema de seguridad.

Al mencionar sobre lo que sea seguridad interna, es necesario comprender las realidades de las discusiones y visiones según Gaspar Tapia: "(...) la crisis centroamericana para muchos era el resultado de procesos internos que se originaban en demandas de participación política y redistribución económica. Sin embargo, para la entonces administración de Ronald Reagan, las diversas crisis de los países centroamericanos no eran más que el resultado del expansionismo soviético monitoreado desde La Habana" (2003: 93).

Al hablar sobre seguridad, es condición primordial partir de la concepción weberiana y durkheimiana del monopolio de violencia desarrollado por el Estado y también de disciplina a los ciudadanos para estos obedezcan las normas y reglas impuestas por grupos dominantes a través de la "coerción directa de los aparatos del Estado", según apunta Sandoval (2007: 198). Para Frade (2008), el crimen está relacionado al descumplimiento de una ley, que es una construcción humana donde el hombre determina lo sea errado conforme sus conceptos internos.

El control social es el punto de partida para entender las dinámicas internas. Según Bobbio (1991), "La ligación particular entre tejidos de las relaciones económicas y reglamentación políticajurídica de las relaciones, que en Hegel es el vinculo ubicado 
Artigo original

Hegemonia - Revista Eletrônica de Relações Internacionais do Centro Universitário Unieuro

ISSN: $1809-1261$

UNIEURO, Brasília, número 10, 2012, pp. 127-157.

completamente en el interior de la sociedad civil"3 (1991: 112). Para el autor en estados de calamidad pública no se puede hablar en seguridad justamente porque el momento es de conmoción general y las prácticas del Estado se cambian para solucionar un grave problema momentáneo. Como por ejemplo en una erupción de un volcán, generando desastres en diversas formas, las instituciones no pueden desarrolla sus acciones de la misma manera en un momento de normalidad en términos de seguridad interna en el Estado.

En contrapartida para Sandoval el equilibrio entre poder político y el poder ciudadano solamente pode ser eficiente cuando hay una credibilidad de ambas partes. En esto sentido, los países marcados por las desigualdades y diferencias sociales donde también la desigualdad a las normas jurídicas son constantes, deben ser observados de manera distinta a la concepción aquí utilizada como metodología de análisis. En estos casos "la producción institucionaliza la violencia y la negación del otro" (2007: 199). Para el autor, la identificación de de un tema de comunicación social auxilia para excluir muchos otros problemas que deben ser nombrados en curto espacio de tiempo, como fue en el caso de la revuelta de los policías en 30 de septiembre para decretar el Estado de excepción.

Con este modelo de actuación, medidas estatales pueden ser ofrecidas para salir de un estado de inseguridad nacional y luego regresar al estado de seguridad, que es la normalidad. Para Giorgi:

$3 \quad$ La traducción es mia. 
Artigo original

Hegemonia - Revista Eletrônica de Relações Internacionais do Centro Universitário Unieuro

ISSN: $1809-1261$

UNIEURO, Brasília, número 10, 2012, pp. 127-157.

"(...) la consolidación de los Estados nacionales, que luego se afirmó en la idea de Estado de derecho y al final ha sido sublimada, como función específica del Estado de bienestar: seguridad de trabajo, seguridad del futuro, seguridad de los derechos sociales, seguridad de la ciudad y un interminable catalogo de seguridad" (1998: 1, en 2007: 201).

Para Bonnewitz, "una teoría jamás se elabora en un vacío social: se inscribe en un contexto particular que modela las problemáticas" (2006: 11). Para la autora es necesario también observar los contextos de las políticas neoliberales y también capitalistas y todo que se proporcionó en cuestiones de seguridad. El crecimiento de la violencia y la inseguridad creó un fenómeno social que afectó el cotidiano de las personas a nivel mundial, conforme apunta Pavarini (2009). Para el autor el fenómeno producido fue la exclusión social donde las desigualdades entre las clases crean estándares desproporcionales sobre lo que sea el imperio de la ley como herramienta de control social.

Siendo así, hay una tensión estructural entre seguridad y libertad que el fenómeno capitalista proporcionó. Cada vez más las personas buscan por mecanismos que solucionen sus demandas por seguridad: candados, cercas eléctricas, cuerpos de seguridad privados, carros blindados, guardas espaldas, armas letales, entre muchos otros ítems. Esta situación puede llevar a una situación del el interés público sea atropellado por interés privados, debido a gran mal del Estado: la corrupción de los actores de los gobiernos. Así se 
Artigo original

Hegemonia - Revista Eletrônica de Relações Internacionais do Centro Universitário Unieuro

ISSN: $1809-1261$

UNIEURO, Brasília, número 10, 2012, pp. 127-157.

hace la confusión entre Estado y gobierno, entendiendo que las acciones del Estado son perenes, mientras que en el caso del gobierno son transitorias.

Pero la seguridad no implica la ausencia de riesgo, depende de cómo se lo estudia. Para Sandoval, "la seguridad es una estrategia de ocultamiento de riesgo. Esto significa que si se conoce el riesgo que se quiere evitar tomando una decisión, no se conoce el riesgo que se corre, con la decisión que se toma para evitarlo" (2007: 204). Así se entiende porque en diversas situaciones de conflictos armados, los Estados se proponen a negarlos para evitar, lo que Ayoob (en: Urgate, 2004: 135) Ilama de "Estado fallido". Así el autor pone que el conflicto en Colombia condiciona que se puede si disponer de un "Estado fallido" ya que la guerra colombiana no deja que acciones del Estado lleguen a todo territorio nacional.

Para el término que determina hasta donde el Estado puede actuar, Ayoob, en una visión realista, determinó tres condiciones a serem destacadas: 1) "la expansión y consolidación del dominio territorial y demográfico bajo una autoridad estatal, incluyendo la imposición del orden sobre un espacio territorial y demográfico disputado (guerra), 2) la preservación del orden en el territorio donde, y sobre la población sobre la cual, tal orden ya ha sido impuesto (actividad policial), 3) la extracción de recursos del territorio y la población bajo el control del estado esenciales para sostener no sólo las actividades de realización de la guerra y policial llevadas cabo por el estado, sino también el mantenimiento de los 
Artigo original

Hegemonia - Revista Eletrônica de Relações Internacionais do Centro Universitário Unieuro

ISSN: $1809-1261$

UNIEURO, Brasília, número 10, 2012, pp. 127-157.

aparatos estatales necesarios para llevar a cabo la administración rutinaria, profundizar la penetración estatal de la sociedad, y servir a propósitos simbólicos (imposición tributaria)" (2004: 137).

De esta forma, el concepto de que sea seguridad pública consigue identificar la amenaza: conflicto armado colombiano. Esta situación crea un escenario de vulnerabilidad que proporciona el resultado de riesgo estatal. Así siendo, el concepto de seguridad sirve para entender la forma en que los grupos humanos históricamente han tratado de enfrentar las amenazas, las vulnerabilidades y los riesgos. Esto para su sobrevivencia y estabilidad una vez que los pilares de la seguridad son: prever, controlar y enfrentar. Ayoob pone en debate el constructivismo de lado al proponer un discurso del realismo periférico (subalterno). Al negar la realidad de un "Estado fallido" se evita determinar la incapacidad de lo actores de gobernar una nación y también para evitar intervenciones internacionales que pueden ser decretadas dentro del Consejo de Seguridad de las Naciones Unidas.

Dentro de los conflictos y, lógico, la seguridad interna, los objetivos de la defensa ecuatoriana está relacionado a aplicación de políticas de desarrollo y combate a la pobreza, al momento de planteamiento de una meta de un discurso desarrollista para la economía, policía y el social. Estas medidas identificaron la amenaza que la desigualdad puede desarrollar para el Estado ecuatoriano. Para Llenderrozas (2008) los países latinos tienen "poco poder en sentido "realista", la participación en las instituciones internacionales difunde 
Artigo original

Hegemonia - Revista Eletrônica de Relações Internacionais do Centro Universitário Unieuro

ISSN: $1809-1261$

UNIEURO, Brasília, número 10, 2012, pp. 127-157.

el poder, proporciona un espacio para la negociación de valores y reglas internacionales" (2008: 483). Para la autora, hay que entender que los países latinos sufren de presiones políticas internacionales de los países desarrollados en perspectivas institucionalistas, lo que ella llama de "poder duro", clasificado como militar y económico.

En términos de legitimidad, la tentativa del reciente golpe en Honduras, las sanciones de la OEA fueron, principalmente, efectivas observando desde una ideología idealista (del deber ser). La visión para el problema en Honduras tuve una óptica realista porque evaluó se sería una buena estrategia, o no, crear una guerra delante de los actos que originaron el conflicto. La percepción de inseguridad está más relacionada con la vida de las personas, e sus día a día, do que para un pensamiento do que se pasa en una guerra.

Para Garibaldi (2008), hay que entender primero todo el contexto de un Estado-Nación para comprender los mecanismos que pueden ser utilizados y también percibir que ni todos los casos no son iguales pero pueden ser utilizados como ejemplos a serem estudiados. Así es necesario observar: "Las sociedades respondían a una necesidad demográfica o social, la urbanización, las migraciones masivas provenientes del campo y que paulatinamente se concentraban en las ciudades. Respondían también a una transformación económica importante, una nueva forma de acumulación de la riqueza: cuando la riqueza comienza a acumularse en forma de stocks, mercadería almacenada y maquinas, la cuestión 
Artigo original

Hegemonia - Revista Eletrônica de Relações Internacionais do Centro Universitário Unieuro

ISSN: $1809-1261$

UNIEURO, Brasília, número 10, 2012, pp. 127-157.

de su vigilancia y seguridad se transforma en un problema insoslayable. Las nueva situación política" (2008: 12).

El autor utiliza la idea foucaultiana donde se ubica las actividades de la policía y su relación con la sociedad del siglo XVII y XVII. Pero puede ser también observar que en siglo XXI muchas de estas preocupaciones continúan para identificar el peligro, enemigo o amenaza y como la legislación penal lo entiende, incluso con relación a la desigualdad social y actuación de las élites para definir como vigilar y castigar el ciudadano. Luego, para entender el proceso de construcción social de un Estado-Nación, que, según Oszlak "la organización de la instancia política que articula la dominación de la sociedad, y la materialización de esa instancia en un conjunto interdependiente de instituciones que permiten su ejercicio" (2004: 16 en 2008: 15).

Para entender las relaciones de la sociedad con los organismos de control del Estado (aquí entendida más para la policía por cuenta de las acciones en América Latina) es primordial tener en cuenta: "la capacidad de externalizar su poder, capacidad de institucionalizar su autoridad, capacidad de diferenciar su control y capacidad de internalizar una identidad colectiva" (Garibaldi, 2008: 15). La idea positivista del orden y progreso es muy utilizada, primeramente en la formación de los paises, pero reproducida para garantizar la intervención de los mismos. Para Garibaldi la condición de análisis de la "seguridad-desarrollo, estabilidad-crecimiento, nuevos rótulos, entre otros tantos, que condensan un mismo y viejo problema: 
Artigo original

Hegemonia - Revista Eletrônica de Relações Internacionais do Centro Universitário Unieuro

ISSN: $1809-1261$

UNIEURO, Brasília, número 10, 2012, pp. 127-157.

garantizar y sostener las condiciones de funcionamiento y reproducciones del capitalismo a través de su despliegue histórico" (2008: 16). Para el autor la utilización de la idea de orden y progreso es eufemística porque no posee la eficacia de orden social porque genera las mismas tensiones que fueron producidas, solamente identifica las amenazas sin encontrar soluciones plausibles.

\section{Seguridad Ciudadana}

Esto término solamente puedo ser utilizado porque el fin de la Guerra Fría traje un escenario, propuesto por los Estados Unidos, para los paises de América Latina y Caribe, fuera lógicamente Cuba. El combate al comunismo generó acciones feroces que originó los gobiernos dictatoriales, principalmente en el Cono Sur, donde el gobierno estadounidense apoyo la nueva dinámica dentro de los paises, hasta finales de la década de los años ochenta. La imposición de la política económica del Consenso de Washington, para los latinos, generó situaciones de austeridades económicas pero con un precio en la gran mayoría de sociedad: pobreza y falta de desarrollo.

Para Neto (2007), las practicas en los procesos de represión, marginalización y exclusión social crearon resultados en la seguridad como producto de estas prácticas. En la década de los años 90 fueron fundamentales para proponer un nuevo modelo que atendiese a una sociedad que sufría mucho con la inseguridad en los centros urbanos 
Artigo original

Hegemonia - Revista Eletrônica de Relações Internacionais do Centro Universitário Unieuro

ISSN: $1809-1261$

UNIEURO, Brasília, número 10, 2012, pp. 127-157.

debido a políticas de exclusión planteadas por los paises por imposiciones externas.

Diversos actores empezaron a trabajar para cambiar el modelo de seguridad pública interna, que sofría de una militarización de los cuerpos policiales con un modelo jerárquico. Esto modelo ya no servía para el contexto democrático evidenciado en los paises latinos. Pero fue la creación de la Comisión de Seguridad Humana en 2001, por la ONU, que una nueva metodología de acción fue propuesta. Esta comisión propuso determinar que el modelo de seguridad estaba equivocado por no mirar las personas como actores primordiales en un contexto de democratización de las sociedades. Utilizando una visión realista, la Seguridad Humana é operativa debido a las intervenciones y sanciones internacionales que pueden ser utilizadas y desarrolladas en contra los paises en desacuerdo.

El modelo a ser desarrollado, buscaba permitir ampliar el marco institucional de intervención del Estado, posibilitando agendas de políticas públicas para posicionaren en acciones conjuntas y no más en separado. Por ejemplo, educación y salud pasaron a no más ser analizadas en distintas direcciones, al revés salud, educación y seguridad son interrelaciónales, sus problemas y soluciones tienen caracteres bien parecidos. A partir de esto enfoque, la solución a los problemas no dimensiona solamente en la definición de los problemas, responsabilidades y estrategias. Tiene que ver, en un primero momento, con la capacidad de articulación y movilización de las instituciones para detectar los problemas, analizarlos, plantear 
Artigo original

Hegemonia - Revista Eletrônica de Relações Internacionais do Centro Universitário Unieuro

ISSN: $1809-1261$

UNIEURO, Brasília, número 10, 2012, pp. 127-157.

soluciones más efectivas, entendiendo que este es un proceso de construcción social con distintos actores sociales.

El concepto de seguridad ciudadana trata, fundamentalmente, de un concepto que lleva la cuestión de prevención en un eje central de sus actividades y así pasa a ser una política de Estado y no más de gobierno, que es transitorio. Entonces, es por esto que se creó una nueva metodología para las policías que solamente se utilizaban acciones represivas. Otra facto insistente, es lo involucramiento de la ciudadanía en iniciativas a desarrollar a nivel local para incrementar las políticas de desarrollo de prevención comunitaria en toda América Latina.

Diversas teorías a respeto de la prevención fueron utilizadas para demarcar, conforme apunta Sozzo (2000), auxiliar las acciones de los representantes políticos para las tomas de decisiones. Neto tiene la siguiente definición: "Dado que la violencia y el delito son fenómenos sociales complejos que no pueden ser enfrentados con una sola estrategia de política pública sino que requieren de un diseño que incluya iniciativas dirigidas a los diversos factores causales, al hablar de factores vinculados al aumento de la violencia y la criminalidad encontramos enfoques que hacen hincapié en la importancia de alguno de ellos, pero que reconocen la necesidad de una estrategia combinada para lograr efectos tangibles y sostenibles en el tiempo" (2007: 27).

La seguridad ciudadana es una teoría que utiliza muchas otras teorías para su aplicación, todavía no contempla una doctrina de 
Artigo original

Hegemonia - Revista Eletrônica de Relações Internacionais do Centro Universitário Unieuro

ISSN: $1809-1261$

UNIEURO, Brasília, número 10, 2012, pp. 127-157.

acción. También es imposible imaginar la aplicación de la seguridad ciudadana a fuera de contextos de la democracia occidental debido a su ideología y metodología. En un Estado liberal también se queda muy difícil su utilización porque se necesita de los mecanismos de la democracia participativa para ubicar las soluciones a serem encontradas. Dahl (1989) dispone de una análisis para identificar los mecanismos a serem desarrollado en una democracia: 1) autoridades elegidas, 2) elecciones libres y justas, 3) sufragio inclusivo, 4) el derecho de candidatear a cargos electivos, 5) libertad de expresión, 6) información alternativa y 7) libertad de asociación (1989: 221). O'Donnell (1996) propone otros tres ítems que complementan la idea de Dahl: i) autoridades elegidas (y algunas nombradas, como jueces de las cortes supremas) no pueden ser destituidas arbitrariamente antes del fin de sus mandatos definidos en la constitución, ii) autoridades elegidas no pueden ser sujetadas a constreñimientos, prohibiciones o excluidas de determinados dominios políticos por otros actores no electos, especialmente las fuerzas armadas y iii) Tener un territorio incontestable que defina a la población que vota.

Estos mecanismos son necesarios serem entendidos para comprender que la teoría de seguridad ciudadana utiliza el contexto del Estado para sus acciones. En contrapartida, una de las más severas críticas al modelo de seguridad ciudadana planteado por los paises latinos, tiene que ver con la realidad impuesta a estos paises debido a los conceptos de centro - periferia. Hasta hoy los latinos 
Artigo original

Hegemonia - Revista Eletrônica de Relações Internacionais do Centro Universitário Unieuro

ISSN: $1809-1261$

UNIEURO, Brasília, número 10, 2012, pp. 127-157.

sufren con los problemas de la colonización europea, como ejemplo las desigualdades sociales y étnicas.

Esta característica local no permite que el principal mecanismo de la democracia participativa sea utilizado con desenvoltura. La participación de los ciudadanos en las distintas esferas de los gobiernos es poco efectiva. Primero porque la credibilidad de la institución policía todavía carece de una nueva realidad, todavía es reciente la opresión de la población por los organismos de la seguridad, principalmente la policía. Otro factor está relacionado a la rendición de cuentas en relaciones horizontales y verticales. Todavía los cuerpos policiales siguen contrarios a esta demanda.

Según Bauman (2001), solamente se puede hablar de sociedad en contexto en que estas se posicionan de acuerdo a la participación. Y una vez en que la comunidad no toma conocimiento de la importancia que el tema de la participación tiene, otros dilemas se evidencian: "No cabe duda de que la libertad sin seguridad no causa menos felicidad que la seguridad sin libertad" (2001: 54). Entonces, aquí se evidencia la diferencia entre seguridad pública y seguridad ciudadana: el motivo de la participación, que es un valor democrático y entre las muchas temáticas a respeto del tema en América Latina, hay también que observar la cuestión del desarrollo.

Diversas propuestas son direccionadas para hacer con que la política pública de seguridad ciudadana sea más efectiva y venga a salir de los planes para serem efectivados. Por esto que los estados buscan incrementar los mecanismos democráticos de la participación 
Artigo original

Hegemonia - Revista Eletrônica de Relações Internacionais do Centro Universitário Unieuro

ISSN: $1809-1261$

UNIEURO, Brasília, número 10, 2012, pp. 127-157.

y disponen de instrumentos para divulgar los actos estatales, como la rendición de cuentas.

Los gobiernos también estimulan los consejos comunitarios barriales como modelo de organización de la sociedad. Otro actor que pasó a cooperar más fue la academia que propone las reformas de los cuerpos policiales. Una de las principales direccione de esta propuesta está en que el modelo de policía militarizada no atiende a la concepción de democracia participativa porque esta institución es muy jerárquica y discriminatoria en su propio interior. Siendo así, una corporación que poco dialoga con sus actores no puede ser efectiva con la comunicación con los actores de la sociedad civil porque se crea una paradoja institucional.

\section{Consideraciones Finales}

Las teorías de seguridad en las relaciones internacionales no son teorías fijas, como por ejemplo el marxismo. Estas teorías siempre se cambian conforme el escenario local, regional, sectorial o mundial. Por esto motivo hay que observar, antes de cualquier cosa, la posición geográfica del país para entonces tejer comentarios sobre el tema.

Este articulo tiene el propósito de discutir los asuntos observar la acción de las Organizaciones de las Naciones Unidas, ONU, después 
Artigo original

Hegemonia - Revista Eletrônica de Relações Internacionais do Centro Universitário Unieuro

ISSN: $1809-1261$

UNIEURO, Brasília, número 10, 2012, pp. 127-157.

de enero de 2001. Este año fue primordial para entender los cambios que ocurrieron con el tema de seguridad, mucho más visibles después del 11 de septiembre de este mismo año en el ataque al World Trade Center.

Los conceptos de seguridad pública y seguridad interna pueden ocurrir no solamente en términos democráticos, que es la primera diferencia entre los conceptos ya que la seguridad ciudadana solamente consigue continuar en contexto democrático y participativo, este último que es la identificación para actuación de los distintos actores sociales: Estado, gobierno, sociedad, policía, academia, entre otros.

La seguridad pública puede ir allá de las fronteras una vez que la intervención por parte de los organismos internacionales puede solicitar apoyo, por ejemplo los cuerpos militares que integran la Minustah. Entonces la seguridad pública puede ofrecer sus cuerpos institucionales y en el caso de seguridad interna puede solamente recibir apoyo. La seguridad ciudadana utiliza solamente cuerpos institucionales nacionales, policía o guardas nacionales, básicamente la policía, todavía hay que observar el país donde está planteada la política pública y sus características nacionales, cómo que tipo de fuerza utiliza para proporcionar la seguridad que puede ser distinta en cada caso particular.

Para Zúñiga (2007) es necesario hacer la diferencia, primeramente, entre las misiones de cada institución para entender como estas deben enfrentar las amenazas. Para la autora las fuerzas 
Artigo original

Hegemonia - Revista Eletrônica de Relações Internacionais do Centro Universitário Unieuro

ISSN: $1809-1261$

UNIEURO, Brasília, número 10, 2012, pp. 127-157.

armadas tienen el lema: atacar, matar o morir en situaciones excepcionales de amenaza a la nación. Mientras que las fuerzas policiales deben hacer uso contenido de la fuerza, a menor escala y su accionar es cotidiano. (2007: 1).

La caracterización de la amenaza es el norte de la acción y donde se clasificará los principios de seguridad pública, seguridad interna o seguridad ciudadana. Por ejemplo, actualmente se discute que el narcotráfico puede ser inserido en estas tres metodologías de acción. Es un problema de seguridad pública, es un problema de seguridad interna y también un problema de seguridad ciudadana. Pueden involucrar la policía o los cuerpos militares. Pueden ser un problema de internacional, frontera, interno o local.

Las agencias políticas de cada Estado van determinar lo que es amenaza y también determinar el tipo de reacción para el enfrentamiento. Son a partir de estas acciones que se pode caracterizar el problema para después involucrar las instituciones pertinentes.

Otra diferencia entre los temas son que: 1) seguridad pública puede ofrecer o recibir cuerpos militares delante de la amenaza, 2) seguridad interna puede solamente recibir refuerzos externos, 3) seguridad ciudadana utiliza solamente cuerpos nacionales, jamás internacionales para resoluciones de sus problemas.

Otra diferencia está relacionada con las teorías a serem utilizadas: 1) Seguridad Pública - realista, constructivista (una vez 
Artigo original

Hegemonia - Revista Eletrônica de Relações Internacionais do Centro Universitário Unieuro

ISSN: $1809-1261$

UNIEURO, Brasília, número 10, 2012, pp. 127-157.

identificada la amenaza), idealista (con el deber ser), puede comprender en contextos liberales, neoliberales o democráticos. 2) Seguridad interna - pueden estar en contextos liberales, neoliberales o democráticos, utiliza la teoría realista para comprensión de sus problemas estructurales. 3) Seguridad ciudadana, aparece solamente en contextos democráticos occidentales, la policía o guardas nacionales desarrollan como actores principales pero entendiendo que esta teoría ponen muchos otros actores y instituciones involucrados en el problema de seguridad.

Al decretar un estado de excepción, como por ejemplo no día 30 de septiembre, estas características se disuelven debido al periodo transitorio que merece más atención delante de la crisis instalada.

Solamente en la seguridad ciudadana se habla de cambios institucionales para atender a la demanda en seguridad. Seguridad pública es el contexto general que crea substratos como la: seguridad interna, defensa, seguridad ciudadana, seguritización, etc. Siendo así se puede decir que la seguridad pública es la doctrina para las demás. Seguridad ciudadana utiliza una seria de teorías, todavía no es una doctrina con una metodología de acción específica. Seguridad interna visa solamente atender los problemas internos pero puede involucrar otras acciones más específicas para resolución del problema.

La seguridad ciudadana abarcar mucho más una visión sociológica de los conflictos do que de una visión de las relaciones internacionales. Esto facto es contrario en comparación a la seguridad 
Artigo original

Hegemonia - Revista Eletrônica de Relações Internacionais do Centro Universitário Unieuro

ISSN: $1809-1261$

UNIEURO, Brasília, número 10, 2012, pp. 127-157.

pública y la seguridad interna: las visiones pueden posee teorías de las relaciones internacionales.

\section{Bibliografía}

Bauman, Sygmunt (2001). La sociedad individualizada. Madrid, Ediciones Cátedra.

Bobbio, Norberto y Michelangelo Bovero (1991). Sociedade e Estado na Filosofia Política Moderna. Brasília, Editora Brasiliense.

Bonnewitz, Patrice (2006). La sociología de Pierre Boudieu. Buenos Aires, Nueva Visión.

Centro de Estudios Legales y Sociales (2004). Políticas de seguridad y justicia penal. Buenos Aires, Siglo XXI Editores Argentina.

Dahl, Robert (1989). Democracy and its critics, New Haven, Yale University Press.

Dammert, Lucía (2007). Perspectivas y dilemas de la seguridad ciudadana en América Latina. Quito, Flacso - Ecuador.

Frade, Laura (2008). Quem mandamos para a prisão (interrogação): visões do Parlamento brasileiro sobre a criminalidade. Brasília, Líber livro Editora.

Fuentes, Claudia y Francisco Rojas (2005). Promover la seguridad humana: marcos éticos normativos y educacionales en América Latina y el Caribe. UNESCO- Flacso. Paris, pp. 27-44. 
Artigo original

Hegemonia - Revista Eletrônica de Relações Internacionais do Centro Universitário Unieuro

ISSN: $1809-1261$

UNIEURO, Brasília, número 10, 2012, pp. 127-157.

Fundación Friedrich Ebert (2006). Seguridad y democracia. Instituto de Investigaciones Sociales, La Paz - Bolivia.

Gaspar Tapia, Gabriel (2003). "Desafíos y dilemas de la seguridad en América Latina en la Posguerra Fría". En Rosas, María Cristina (coord.) Cooperación y conflicto en las Américas. Seguridad Hemisférica: Un largo y sinuoso camino. México, Universidad Autónoma de México, pp. 91-114.

Giorgi, Raffaele de (1998). "De riesgo de la inseguridad al riesgo del descontrol". Conferencia dictada en el Seminario sobre la Teoría de los Sistemas, México, UNAM, Facultad de Ciencias Políticas, inédito, p.1, en: Sandoval, Sánchez (2007). "Políticas públicas en materia de seguridad, en: La sociedad del riesgo". En: Germán Cisneros et al. (coords.) Seguridad pública: segundo Congreso Iberoamericano de Derecho Administrativo. México, Universidad Autónoma de México, pp. 193-220.

Legler, Thomas (2003). "Víctimas del terrorismo (interrogación). La seguridad humana después del 11 de septiembre", en Rosas, María Cristina (coord.) Cooperación y conflicto en las Américas. Seguridad hemisférica: un largo y sinuoso camino. México, Universidad Autónoma de México, pp. 283-299.

Llenderrozas, Elsa (2008). "Instituciones y cooperación subregional del Cono Sur frente a amenazas transnacionales. Una comparación con la experiencia en Haití, en: Vélez, Fredy Rivera (2008). Seguridad Multidimensional en América Latina. Flacso - Ecuador. 
Artigo original

Hegemonia - Revista Eletrônica de Relações Internacionais do Centro Universitário Unieuro

ISSN: $1809-1261$

UNIEURO, Brasília, número 10, 2012, pp. 127-157.

Neto, Paulo de Mesquita (2008). Ensayos sobre seguridad ciudadana. Flacso - Ecuador.

O’Donnell, Guillermo (1996). "Ilusions about consolidation", journal of democracy, 7 n. 2, pp. 34-51.

Orozco, Gabriel (2006). "El concepto de seguridad en la Teoría de las Relaciones Internacionales". En Revista CIDOB dÁffers Internacionals. 72, pp. 161-180.

Pavarini, Massimo (2009). Castigar el enemigo: criminalidad, exclusión e inseguridad. Quito, Flacso - Ecuador.

Pontón, Daniel (2009). Policía comunitaria y cambio institucional en el Ecuador. Flacso - Ecuador.

Sandoval, Sánchez (2007). "Políticas públicas en materia de seguridad, en: La sociedad del riesgo". En: Germán Cisneros et al. (coords.) Seguridad pública: segundo Congreso Iberoamericano de Derecho Administrativo. México, Universidad Autónoma de México, pp. 193-220.

Sozzo, Máximo (2000). "Seguridad urbana y tácticas de prevención del delito", cuadernos de doctrinas y jurisprudencia penal. Buenos Aires, Ad-Hoc, n.10, pp. 103-136.

Urgate, José Manuel (2004). Los conceptos jurídicos y políticos de la seguridad y la defensa: un análisis orientado a América Latina. Buenos Aires, Editorial Plus Ultra, pp. 79-152. 
Artigo original

Hegemonia - Revista Eletrônica de Relações Internacionais do Centro Universitário Unieuro

ISSN: $1809-1261$

UNIEURO, Brasília, número 10, 2012, pp. 127-157.

Vélez, Fredy Rivera (2008). Seguridad Multidimensional en América Latina. Flacso - Ecuador.

Zúñiga, Liza (2007). Defensa y seguridad: ¿Militares o policía? Flacso 